DE DE GRUYTER OPEN

U

LINGUACULTURE 1, 2014

\title{
PSYCHOLOGY AND ADAPTATION: THE WORK OF JEROME BRUNER
}

\author{
LAURENCE RAW \\ Başkent University, Ankara, Turkey
}

\begin{abstract}
This article offers a view as to why Jerome Bruner should become an important figure in future constructions of adaptation theory. It will be divided into three sections. In the first, I discuss in more detail his notions of transformation, paying particular attention to the ways in which we redefine ourselves to cope with different situations (as I did while visiting two specific museums in Vienna and Samos). The second will examine Bruner's belief in the power of narrative or storytelling as ways to impose order on the uncertainties of life (as well as one's expectations from it) that renders everyone authors of their own adaptations. In the final section I suggest that the capacity for "making stories" (Bruner's term) assumes equal importance in psychological terms as it does for the screenwriter or adapter: all of us construct narratives through a process of individual distillation of experiences and information, and subsequently refine them through group interaction. Through this process we understand more about ourselves and our relationship to the world around us. I elaborate this notion through a brief case-study of Charlie Kaufman's screenplay for the film Adaptation (2002).
\end{abstract}

Keywords: psychology, adaptation, collaboration, storytelling

To date most work on adaptation has focused on the film-media studiesliterature paradigm. Even though we have moved away from hackneyed questions of fidelity towards intertextuality and/or the ways the adaptive act is shaped by industrial and other cultural concerns, there is still a reluctance to acknowledge other constructions of adaptation. I was made acutely aware of this during the summer, when I visited the Kunsthistorisches Museum in Vienna. Opened in 1891 at the same time as the Naturhistorisches Museum by Emperor Franz Joseph I of Austria-Hungary, it was designed to show off the Habsburg's fashionable art collection and to make it accessible to the general public. The inside of the building was lavishly decorated with marble, stucco ornamentations, gold-leaf and paintings, not only to emphasise the wealth of the Habsburg monarchy, but to make visitors understand precisely what it meant to

DOI: $10.1515 /$ lincu $-2015-0018$ 
be a member of the aristocratic class. As they entered the museum, they felt inadequate when faced with ornamented walls festooned with portraits of the Royal Family past and present.

The same experience confronts the tourist today: one wrote that: "The [museum] stairway alone could worth the visit. Everything spells beauty, grandeur, fine taste [...] It was an immense pleasure to walk through beautiful halls $[. .$.$] while admiring the many masterpieces" ("Top Class Museum"). When$ I was first confronted with the stairway, I felt intimidated by the sight of all the faces gazing down at me from the walls; like a commoner entering the royal court, perhaps I should be kneeling in front of them. As I walked through the galleries, however, my responses changed; as I looked at the paintings, especially Pieter Bruegel the Elder's "The Tower of Babel" (c. 1563), I began to appreciate the artist's ability to create an image with particular significance today. Bruegel painted a portrait of a building whose arches seem unstable; some of them are almost crumbling. The hectic activity of the workers trying to repair these faults suggests the futility of human endeavour. The same can also be said of many of the contemporary building projects in my home city - Ankara in Turkey - which are equally poorly constructed. As I look out of my window as I write, I see building workers hammering wooden frames together in preparation for yet another concrete block; I wonder whether their efforts will prove as futile as those depicted by Bruegel. The experience of looking at "The Tower of Babel" changed my view of the Kunsthistoriches Museum; I was no longer apprehensive but instead admired the work of those whose work had been commissioned by the Habsburg monarchy. I had undergone an adaptive process; the situation might have been the same but my position within it had changed through experiencing a different emotional feeling. This exercise in "trusting emergence" allows for the presence of uncertainty as a means to obtain "a ringside seat on what is happening that gives us much more data [emotional as well as intellectual] for informed decision-making" (Arpa 76).

I experienced a similar feeling later on while visiting the Archaeological Museum in Samos, one of the Greek islands. Housed in two buildings - the Old Museum built in 1912, and the New Museum, inaugurated in 1987 - the museum offers a fascinating contrast between the 4.75 meter sculpture (orkouros) from ancient Greece, with the late nineteenth century ambiance of the buildings. Anyone expecting the hushed, reverential atmosphere associated with more established museums (even the Antalya Museum in the south of Turkey) is in for surprise; for a first-time visitor like myself, the experience was more like entering someone's summer-house stuffed full of treasures. Once again I had to adapt myself to get used to unfamiliar surroundings, and through that process learned to look at the world once again with open eyes (Williams and Penman 31).

This approach to adaptation has been developed by cognitive psychologist Jerome Bruner, whose books The Culture of Education (1995), and Making 
Stories (2002) posit a significant theoretical link between the process of transforming oneself to new material and/or environments, and the practical aspects of transforming texts across media. Bruner was one of the main advocates of the constructivist approach to knowledge acquisition - an active process of constructing new ideas and concepts based on existing beliefs. Facets of this process include selection and transformation of information, decisionmaking, and making meaning from information and experiences - precisely the same kind of abilities which are required in the creation of a transmedial adaptation. In her piece "The Screenplay in the Digital Era," Kathryn Millard quotes a variety of authorities, all of whom posit a "theory of creativity" in screenplay writing derived from cognitive psychology, involving an interplay between the developing work and the mind of the artist/ adapter: sometimes different types of information and experience help the work to find its own shape in the process of creation (Millard 18).

This article offers a view as to why Jerome Bruner should become an important figure in future constructions of adaptation theory. It will be divided into three sections. ${ }^{24}$ In the first, I discuss in more detail his notions of transformation, paying particular attention to the ways in which we redefine ourselves to cope with different situations (as I did while visiting the museums in Vienna and Samos). The second will examine Bruner's belief in the power of narrative or storytelling as ways to impose order on the uncertainties of life (as well as one's expectations from it) that renders everyone authors of their own adaptations. In the final section I suggest that the capacity for "making stories" (Bruner's term) assumes equal importance in psychological terms as it does for the screenwriter or adapter: all of us construct narratives through a process of individual distillation of experiences and information, and subsequently refine them through group interaction. Through this process we understand more about ourselves and our relationship to the world around us. ${ }^{25}$ I elaborate this notion through a brief case-study of Charlie Kaufman's screenplay for the film Adaptation (2002).

Before doing so, however, it might be worthwhile to deconstruct the notion of transformation and emphasise its relationship to adaptation. Jack Mezirow believes that "perspective transformation," involves a structural change in the way human beings view themselves and their relationship to the world

\footnotetext{
${ }^{24}$ Much of the material for this chapter is based on the piece written by Tony Gurr and myself - "Why Bruner Matters" - in Adaptation and Learning: New Frontiers. Lanham, MD: The Scarecrow Press, 2013: 75-85.

${ }^{25}$ Suzanne Diamond refers to Bruner's concept of narrative construction with particular reference to adaptation studies in "Whose Life is it, Anyway?" in Redefining Adaptation Studies. Eds. Dennis Cutchins, Laurence Raw, and James M. Welsh. Lanham, MD: The Scarecrow Press, Inc., 2010: 95-111.
} 
around them; this process reformulates the criteria for valuing and for taking action by moving away from uncritical, organic relationships toward contractual relationships with others, institutions and society. Such changes involve learning "how to negotiate and act upon our own purposes, values, feelings and meanings rather than those we have uncritically assimilated from others" (Mezirow and Associates 8). To take my experience in the Samos Museum as an example, I felt transformed once I had learned how negotiate and ultimately adapt my received opinions about the experience of walking through an institution devoted to classical antiquities. On this view, transformation occurs as a result of adaptation, a process that is primarily rational, analytical, and cognitive. This transformation might be most concisely summed up as a process of acceptance, allowing us to respond to new experiences and find the best ways of dealing with them. Rumi, the thirteenth century poet, summed up this in the poem "The Guest House":

This being human is a guest house, Every morning a new arrival.
A joy, a depression, a meanness,
Some momentary awareness comes
as an unexpected visitor [....]
Be grateful for whatever comes, because each has been sent as a guide from beyond (Rumi 164-5)

Bruner would agree with Rumi's belief that adaptation and transformation involve accommodating new experiences into one's life through narrative creation.

Bruner's thinking owes a lot to the writings of Russian educational theorist L. B. Vygotsky, who approached adaptation from a socio-cultural rather than a cognitive perspective. He believed firmly believed that knowledge was constructed by the subject rather than being simply "out there." As children we acquire new knowledge inter-psychologically through association with others. This knowledge is adapted intra-psychologically, as we reflect on our interpsychological experiences and make sense of them. One way to promote this might be through socio-dramatic play, in which we choose a plot that reflects a certain aspect of social relations (e.g. buying something in a store), distribute roles, and play together, working out as we do so what kind of social relations should be involved. We do what we want, liberating ourselves from any externally applied rules and social pressure. As we play, we learn how to adapt ourselves to new situations and by doing so "penetrate" the world of adults through imitation (Karpov 59). 
Following Vygotsky, Bruner stressed the importance of the social setting in the ways in which we adapt to new phenomena. In The Process of Education (1960), he proposed a model of learning based on the spiral metaphor: we should continually return to basic ideas as new subjects and concepts are introduced, as means of solidifying understanding and increasing our confidence. His notion was based on the belief that human cognition evolved in a step-by-step process of learning through group interaction and real-world experience. The spiral metaphor reinforces belief in group dynamics as a means of making sense of the world, as well as the need to revisit core concepts so as to help us understand them in greater depth. Applying this model to the socio-dramatic play of buying something in a store, we adapt ourselves to new situations by encountering new situations and evaluating them in terms of received knowledge. Once that process has been accomplished, then we will hopefully have acquired sufficient confidence to adapt ourselves.

Bruner emphasises the power of intuitive as well as analytical thinking in this process, more precisely defined as "the intellectual technique of arriving at plausible but tentative formulations through the analytical steps by which such formulations would be found to be valid or invalid conclusions" (Process 13). This is observable in young children and experts, who "leap intuitively into a decision or solution to a problem" (13). The spiral metaphor offers a means of rationalizing how and why our intuitive thoughts are refined in the light of increased knowledge and/or awareness. The fact that such opportunities are provided greatly enhances our willingness to learn; we are not so much concerned with "external goals as grades or later competitive advantage," but stimulated by "interest in what there is to be learned" (80). Analysing my experiences in Vienna according to Bruner's ideas, my first experience of entering the Kunsthistorisches Museum evoked a spontaneous response. It was only when I refined my thoughts further - by entering the museum and looking more closely at the exhibits - that I came to make sense of what I saw. I held myself open in an enquiring way; like an explorer I mapped the historic terrain, its crags and valleys, its patterns and its faults, and discovered a way through it through adaptation (Williams and Penman 174).

Three decades later in The Culture of Education, Bruner explained why this approach was so significant: adaptation is part of culture, and culture "shapes the mind $[\ldots]$ it provides us with the toolkit by which we construct not only our worlds but our very conception of ourselves and our powers" (Culture $x)$. Adaptation should make us aware of our own thought processes; thus we should construct our lives to facilitate this process. It is not enough to acquire knowledge or cultivate abilities: we should become "metacognitive" - in other words, acquiring the confidence to reflect on how well we cope with particular tasks, as well as determining what measures we might take to improve ourselves 
(Culture 64). This might be achieved through group reflection as well as reflection. Although written in a very different era - and providing the basis for the experiments conducted in American education throughout the 1960s Bruner's theories prove especially fruitful in thinking about adaptation studies. ${ }^{26}$ His use of the spiral metaphor implies a nonlinear process of transformation, wherein present concepts and future aspirations are regularly reinterpreted in the light of past knowledge. This kind of reflection lies at the heart of any interaction, whether it involves us in the process of trying to adjust to the outside world, reading texts, or communicating with friends and acquaintances in groups - whether face-to-face or online. To encourage this process of metacognition, we should strive for openness, and thereby understand more clearly what adaptation involves. Reading Bruner before I went to Vienna proved particularly beneficial for me; earlier on this year I had experienced the kind of serious illness that led me to speculate on my future both personally and professionally. Learning how to adapt enabled me to have a conversation with "the critical voices" within me, to work out why they were telling me such negative things about myself, to engage with them and try and find a way of transforming my state of mind (Sutton 278-9). Through such processes I learned how to transform my feelings of apprehension into more positive emotions.

What makes Bruner so interesting, however, is his emphasis on investigating the social and psychological processes shaping any adaptive act; and how our understanding of such processes is never fixed, but depends very much on our subject position. To understand that position, and how it determines our relationship to the world around us, is an intrinsic aspect of metacognition. Bruner argues that the most effective means is to treat our adaptive acts as narratives, designed to "resolve the unexpected, [...] settle the auditor's doubt, or in some manner [...] redress the 'imbalance' that prompted the telling of the story in the first place" (Culture 121). Narrative renders the strange familiar, transforms uncertainty into certainty, normalises the unexpected. We can only grasp the significance of the spiral metaphor if we can transform new ideas into a story form, shaped by our existing knowledge (121). In Making Stories (2002) Bruner develops this theory at length: narratives not only help us make sense of the world but transform experiences into "collective coin which can be circulated $[\ldots]$ Being able to read another's mind need depend no longer on

${ }^{26}$ Bruner became involved in the design and implementation of the influential MACOS project (which sought to produce a comprehensive educational curriculum drawing upon the behavioural sciences). The curriculum famously aimed to address three questions: (i) what is uniquely human about human beings; (ii) How did they get that way; and (iii) How could they be made more so through adaptation. The project involved a number of researchers, but was attacked by conservative educationalists on the grounds of lack of subject specificity. It was also difficult to implement, involving a long program of teacher training and motivation. 
sharing some narrow or interpersonal niche but rather on a common fund" (Making Stories 16). Group interactions thrive on the interplay of narratives, on the sharing of common ideas that "come to terms with the breach [i.e. the unexpected or the uncertain] and its consequences," producing an outcome or resolution (17).

Bruner expounds his theory by suggesting that narrative gives us the power to make sense of things, even when they don't appear to make much sense, citing the psychologists George A. Miller, Karl H. Pribram and Eugene Galanter to support his point. They believe that narratives are an expression of the desire to plan, "the elementary neuro-psychic unit of human consciousness and action" (28). Planning requires a working knowledge of how our world works and, more importantly, how others will react: "thanks to the regularizing power of culture, our plans usually work out quite quietly and well" (28). This is why group interactions are intrinsic to our lives, for it is only by regular association with others that we can (largely) guarantee the success of a plan or narrative. Telling others about ourselves and our feelings transforms our ideas of who we are, what happens, and explanations about what we are doing at any given moment into story form. Talking about or (as in my case) writing about experiences helps us to "step outside the chattering negative self-talk and [...] reactive impulses and emotions. It allows [us] to look at the world once again with open eyes [...] [producing] a sense of wonder and quiet contentment" (Williams and Penman 31).

However narratives do not always comprise the familiar; we often construct them in such a way as to "create a conviction of autonomy, that one has a will of one's own, a certain freedom of choice, a degree of possibility" (78) ${ }^{27}$ This is what might be termed the desire for originality. In Bruner's view our concept of narrative creation is dominated by contradictory forces: autonomy (i.e. the desire to be original) and our commitment to group values (that frequently depend on sacrificing autonomy in favour of familiarity). How we resolve that conflict is very much down to choice: some create original narratives by freeing ourselves from "precedent obligations" to the familiar and opting for "a self-generated peripeteia" instead (83). This may engender "new trends and new ways of looking at ourselves in the world" (84).

Bruner suggests that these competing narratives (original vs. familiar) help us make meaning; they are the basis for communal life yet can simultaneously threaten those who try to sustain that community. Hence strategies have to be developed for negotiating such conflicts - for example, legal systems that restrict "incompatible interests and aspirations" (93). As individuals, we can either accept such structures - that reinforce community values - or create "self-defining" adaptive narratives of our own. Bruner invokes

${ }^{27}$ This suggests emotional as well as rational involvement. 
a term coined by Claude Lévi-Strauss to describe all human beings; they are "bricoleurs" (90) - improvisers, creators of narratives designed to "tell about ourselves to ourselves," while remaining loyal to the group networks surrounding them. Sometimes our narratives invoke "old stories" as a means of dealing with the unfamiliar; occasionally they incorporate entirely new stories of our own creation. More often than not they combine both elements.

Bruner's theory of narrative formation applies equally to the adaptive act of transforming a work of literature into film. Narratives constructed from the source text is transformed into "collective coin" (Bruner's term) by means of a set of familiar conventions - for example, the three-act structure - which are perpetuated within 'how to' screenwriting manuals, screenwriting courses and film and television commissioning and funding bodies. Through feedback from others involved in the filmmaking process - producers, directors, studio bosses, actors, and so on - that screenplay is subsequently reshaped according to a "common fund" of beliefs that challenge the adapter's status as a primary creative force, as well as affecting their ability to retain control of their own work. Carol Wolper recommends any aspiring writer to "learn how to adapt and follow through"; to seek out new opportunities, try new methods and take note of peer advice: "You don't have to agree with everything they say [...] but if they feel they are talking in vain, they'll move on" $(7,14)$. Such suggestions evoke Bruner's observations about the importance of revising self-narratives in line with prevailing conventions. Wolper emphasises the importance of cultivating new ideas through adaptation: "The brain can be re-tooled. Old habits don't have to die painfully. It's amazing how an addiction to freedom and working for yourself can cure you of attachment" (27). To acquire the ability to adapt and possibly change the way the act of screenplay writing is viewed are tantalizing prospects that can help us "take stock of all the things [...] [they] have going as a way of reconnecting to the foundation of [...] self-esteem" (42). For Wolper the adaptive act represents "FREEDOM and inspiration" (60). Bridget Conor concurs: "screenwriters are able to exercise creative autonomy and freedom not possible for many other film production workers; they can and do experience fruitful collaborations with fellow creative and may be rewarded with [...] critical rewards and recognition" (39). It is this mix of constraint and reward, exploitation and autonomy that renders the profession so fascinating.

Charlie Kaufman's screenplay for Adaptation (2002) offers a good example of how this process might work in practice. Ostensibly based on Susan Orlean's true story of The Orchid Thief (1998), it recounts Kaufman's struggles to transform a source-text into a triumph of originality rather than a mélange of Hollywood screenwriting conventions. Kaufman himself has been quoted as saying that "the emotions that Charlie is going through [in the film] are real and they reflect what I was going through when I was trying to write the script" (Screenplays 7). Charlie (Nicolas Cage) begins by asserting that the very act of 
adaptation - transforming someone else's work into a classical three-act screenplay - somehow compromises his talent as a writer as well as his need to "think about the world in a different way" (Kaufman and Kaufman 9). This selfdoubt quickly mutates into more existential reflections on the meaninglessness of his life: "I am fat. I am repulsive. I cannot bear my own reflection" (16). His private thoughts are set against his conversations with film executive Valerie Thomas (Tilda Swinton), in which asserts his independence as a screenwriter who doesn't want to make the film "artificially plot driven $[,,$,$] or cramming in$ sex, or car chases, or guns. Or, characters learning profound life lessons. Or characters growing or characters changing or learning to like each other [...] Y'know? Movie shit" (6). In Brunerian terms, Kaufman constructs two parallel narratives: the public narrative, wherein he conceives himself as a creative artist (justifying the salary paid to him by the studio); and the private narrative, where he feels trapped by the "common fund" of belief that forces him to write in a certain way. The film suggests that Darwin can help to resolve this mental conflict. In one sequence Charlie is shown picking up a copy of The Portable Darwin (1993) from the floor; we hear him in voiceover musing about the need in his screenplay to depict the arc of a flower. The action cuts abruptly to the late nineteenth century, as the reincarnated Darwin (Bob Yerkes) sits in his study, pronouncing that "all the organic beings which have ever lived on this earth are descended from one primordial form into which life was first breathed" (37). We return to the present to witness Charlie experiencing a moment of inspiration; depicting a flower represents "the journey of evolution. Adaptation. The journey we all take. A journey that unites each and every one of us. ${ }^{28}$ He has understood the power of adaptive thinking; change the narrative you construct to make sense of particular phenomena, and you can change your outlook on life, especially if you view the world through a Brunerian model of transformation. In a wonderfully self-reflexive climax - where we witness Charlie leaving his apartment while listening to him describing his actions in voiceover as if he were a character in his own screenplay - he observes that he now "knows how to finish his script [...] It feels right. Conclusive [...] It's done. And that's something. So: 'Kaufman drives off from his encounter [...] filled for the first time with hope. ${ }^{\prime 29}$ In a recent piece relating Adaptation to Northrop Frye's conception of the "inductive leap", ${ }^{30}$ Timothy A. DeJong sums up the experience of this moment: "beneath its seeming navel-gazing the film is, I believe, saying

28 This line occurs in the finished film Adaptation but not in the 1999 draft of the screenplay (from which all other references are cited).

${ }^{29}$ These lines are once again taken from the finished film not the draft screenplay.

${ }^{30}$ Frye believed that every reader of literary or any other texts made this kind of leap, a process "from which we can discover what the organizing or containing forms of its [the text's] conceptual framework are" (16). 
[...] that the assumptions we make about the function of [adapting] literature prove to be a significant, even determining factor in how we perceive and interact with the world around us" $(70){ }^{31}$

Bruner identifies several parallels between storytelling in different media, including cinema, and the human tendency toward narration. They include: the desire to analyse intentions, aspirations and set personal goals; the need to overcome obstacles to achieve those goals; the need to impose coherence on disparate experiences, and the tendency to rewrite the past in accordance with present conditions. In a story (or a screenplay), as in life, plots, intentions and resolutions are important, while obstacles help sustain interest, as well as forcing protagonists to adapt their past beliefs. Fictional stories and narratives also require continuity to sustain interest; while only the "story relevant past" is significant for the present (Making Stories 72). Through such strategies Bruner offers us a means by which to relate the process of adapting texts and the psychological aspects of adaptation studies - a theoretical path which has yet to be explored in any great depth. ${ }^{32}$ He believes that narrative lies at the heart of all psychological, spoken and written interactions, helping us to make sense of the world around them, as well as promoting innovative ways of thinking. As they encounter material, they adapt their existing narratives by "altering [...] aspirations and changing [...] reference[s]." Yet this process is not accomplished in isolation: we reconsider our narratives through interaction with "reference groups" - friends, family, acquaintances, fellow-workers - and "significant others" such as directors and producers in the cinematic context. Bruner underlines the flexibility of narratives; they can be "possessive and extensible, adopting beliefs, values, loyalties, even objects as aspects of their own identity," while being simultaneously capable of "shedd[ing] these values and possessions [...] without losing the continuity" (72). Bruner exemplifies the point through a comparison of writing literature and practicing the law. Both professions require the ability to construct narratives, albeit for different purposes: literature favours the possible, the figurative, and the imaginative, while the law looks to the actual as a record of the past. However that term "actual" can be contested - as happens, for instance, in any court when the prosecuting and defending counsels try to win their cases by offering different interpretations of the evidence. With this in mind, Bruner argues that both literature and law are prone to "refreshment

31 Cf. David L. Smith's observation on the film's ending: “Adaptation, then, is a meditation on the extent to which a story can do justice to a human life" (425).

32 Adaptation studies could be best advised to follow the theoretical example of ecocritic Glen A. Love, whose article "Ecocriticism, Theory and Darwin," explicitly applies Darwinian ideas of adaptation, especially the process of individuals adjusting to their environment, to literary texts. His work Practical Ecocriticism (2003) develops these ideas in more detail. I am grateful to Scott Slovic for these references. 
and reshaping" over time: like literary fashions that come and go, the style of legal pleading and judgment also changes. Although the content of both is obviously very different, Bruner believes that they require a similar facility for narrative (re-)construction, lending weight to his claim that "a culture's narrative dialectic expresses itself [and can be readily understood from] [...] the imaginative works of writers and playwrights" (62).

Adapting narratives is neither restricted to one or two disciplines within the humanities, nor confined to the screenwriter charged with altering a text for filming; it is an ability that dominates all of our lives. The filmmaking process is dominated by adaptive processes, as screenplays are shaped and reshaped to accommodate the requirements of producer, director, actors and other creative artists, as well as distributors and marketers. ${ }^{33}$ The final product - i.e. the text that appears in the completed film - is arrived at through a process of collaboration, a process that continues when the film is distributed and redistributed in different socio-economic contexts.

In the light of his preoccupations over five decades of writing, we might ask why Bruner has not hitherto formed part of adaptation studies' theoretical agenda. The reason we believe has to do with a reluctance to think transdisciplinarily: to a large extent his writings have concentrated on the fields of law and educational psychology rather than media, literature, or film studies. What my experiences in Vienna and Samos revealed, however, is there exists considerable potential for expanding adaptation studies' theoretical agenda to encompass text-based approaches, as well as psychological analyses focusing on how and why we need to adapt throughout their lives - not just when they are creating adaptations or watching adaptations of films or television programs. In a recent book criticizing many adaptation studies theorists for making "hasty generalizations" in their work, Patrick Cattrysse calls instead for more considered approaches (133). In his view this can be provided by Direct Adaptation Studies (DAS), a framework based largely on the work of translation theorist Gideon Toury (among others). Whereas I have commented elsewhere on the merits and demerits of this approach, ${ }^{34}$ I believe that Cattrysse is right in calling for more particularised theoretical material. The Bruner-inspired model of adaptation offers a way forward, as it explicitly focuses on the dialectic between ourselves and the communities we inhabit. From a personal point of view, my experience of working with Bruner has rendered me more "mindful," in the sense that I have come to understand the cultures I inhabit and make choices about what I can buy into, what I will go along with, and at what point I

${ }^{33}$ The role played by creative artists in adaptation $v i s$ - $a$-vis industrial players has been debated by Simone Murray in The Adaptation Industry.

34 See my review of Descriptive Adaptation Studies in Literature/ Film Quarterly, forthcoming ("My Theory Can Lick Your Theory.") 
no longer wish to participate (Arpa 82). Using a similar framework in the analysis of film adaptations, we can discover how screenplay writers - as with other creative artists - makes similar choices while transforming a source-text, choices that are determined not only by individual preferences, but by the cultures that shape their judgments. This mode of analysis is highly significant in a rapidly changing world, where technological advances have enabled us to question hitherto fixed boundaries (between the individual and society, source and target texts, literature), as well as rethinking the difference between 'academic' and 'non-academic' ways of thinking.

\section{WORKS CITED}

Adaptation. Dir. Spike Jonze. Perf. Nicolas Cage, Meryl Streep, Tilda Swinton. Columbia TriStar Home Video, 2003. DVD.

Arpa, Maria. Mindfulness at Work: Flourishing in the Workplace. Lewes, UK: Leaping Hare Press, 2013. Print.

Bruner, Jerome. The Culture of Education. Cambridge, MA: Harvard UP, 1996. Print.

-----. Making Stories: Law, Literature, Life. Cambridge, MA: Harvard UP, 2002. Print.

-----. The Process of Education. 1960. Cambridge, MA: Harvard UP, 1977. Print.

Cattrysse, Patrick. Descriptive Adaptation Studies: Epistemological and Methodological Issues. Antwerp and Apeldoorn: Garant, 2014. Print.

Conor, Bridget. "'Everybody's a Writer: Theorizing Screenwriting as Creative Labour." Journal of Screenwriting 1.1 (2010): 27-43. Print.

Darwin, Charles. The Portable Darwin. Eds. Duncan M. Porter and Peter W. Graham. Harmondsworth: Penguin Books, 1993. Print.

DeJong, Timothy A. "Between the Is and the Is Not: Northrop Frye, Adaptation and the Romantic Imagination." English Studies in Canada 37.2 (June 2011): 67-86. Print.

Diamond, Suzanne. "Whose Life is it, Anyway?" Redefining Adaptation Studies.Eds. Dennis Cutchins, Laurence Raw and James M. Welsh. Lanham, MD: The Scarecrow Press, Inc., 2010. 95-111. Print.

Frye, Northrop. Anatomy of Criticism: Four Essays by Northrop Frye. Princeton: Princeton UP., 1957. Print.

Karpov, Yuriy V. Vygotsky for Educators. Cambridge: Cambridge UP, 2014. Print.

Kaufman, Charlie, and Kaufman, Donald. "Adaptation: Adapted from the book The Orchid Thief by Susan Orlean." Second Draft Screenplay, Sep. 24, 1999. Dailyscript.com. Web. 5 Jul. 2012.

Love, Glen A. “Ecocriticism, Theory, and Darwin.” ISLE 17.4 (2010): 773-5. Print.

-----. Practical Ecocriticism. Charlottesville: U. of Virginia Press, 2003. Print.

Mezirow, Jack, and Associates.Learning as Transformation. San Francisco: JosseyBass, 2000. Print.

Millard, Kathryn. "After the Typewriter: The Screenplay in the Digital Era.” Journal of Screenwriting 1.1 (2010): 11-25. Print.

Murray, Simone. The Adaptation Industry: The Cultural Economy of Contemporary Literary Adaptation. New York and Abingdon: Routledge, 2011. Print. 
Orlean, Susan. The Orchid Thief: A True Story of Beauty and Obsession. New York: Vintage, 1998. Print.

Raw, Laurence. "My Theory Can Lick Your Theory." Literature/Film Quarterly, forthcoming. Print.

-----, and Tony Gurr. Adaptation and Learning: New Frontiers. Lanham, MD: The Scarecrow Press, 2013. Print.

Rumi, Jalaluddin. "The Guest House." Trans. Coleman Barks. Mindfulness: A Practical Guide to Finding Peace in a Frantic World. 164-5. London: Piatkus, 2011. Print.

Screenplays by Charlie Kaufman, Including, Human Nature (Film), Adaptation (Film), Being John Malkovich, Eternal Sunshine of the Spotless Mind, Confessions of a Dangerous Mind, Synecdoche, New York. New York: Hephaestus Books, 2009. Print.

Smith, David L. “The Implicit Soul of Charlie Kaufman's Adaptation.” Philosophy and Literature 30.2 (October 2006): 424-35. Print.

Sutton, Jan. Healing the Hurt Within: Understand Self-Injury and Self-Harm, and Heal the Emotional Wounds. Oxford: How to Books, 1999. Print.

“Top Class Museum.” Tripadvisor, 30 Aug. 2014. Web. 5 Sep. 2014.

Williams, Mark, and Danny Penman. Mindfulness: A Practical Guide to Finding Peace in a Frantic World. London: Piatkus, 2011. Print.

Wolper, Carol. Adapt or Wait Tables: A Freelancer's Guide. Los Angeles: Rare Bird Books, 2013. E-book. 